\title{
REVIEW
}

\section{Modeling Alzheimer's disease with non-transgenic rat models}

Laurent Lecanu',2,* and Vassilios Papadopoulos, ${ }^{1,2,3}$

\begin{abstract}
Alzheimer's disease (AD), for which there is no cure, is the most common form of dementia in the elderly. Despite tremendous efforts by the scientific community, the AD drug development pipeline remains extremely limited. Animal models of disease are a cornerstone of any drug development program and should be as relevant as possible to the disease, recapitulating the disease phenotype with high fidelity, to meaningfully contribute to the development of a successful therapeutic agent. Over the past two decades, transgenic models of AD based on the known genetic origins of familial AD have significantly contributed to our understanding of the molecular mechanisms involved in the onset and progression of the disease. These models were extensively used in AD drug development. The numerous reported failures of new treatments for $A D$ in clinical trials indicate that the use of genetic models of $A D$ may not represent the complete picture of $A D$ in humans and that other types of animal models relevant to the sporadic form of the disease, which represents $95 \%$ of AD cases, should be developed. In this review, we will discuss the evolution of non-transgenic rat models of $A D$ and how these models may open new avenues for drug development.
\end{abstract}

\section{Introduction}

Alzheimer's disease (AD) is a progressive and irreversible debilitating form of dementia. It is characterized by progressive memory impairment and diminished cognitive performance. Non-cognitive neurological comorbidities often include depression, aggression, and/or psychosis. Histological alterations of the brain tissue

*Correspondence: laurent.lecanu@mcgill.ca

'The Research Institute of the McGill University Health Centre, Royal Victoria Hospital, 687 Pine avenue West, room L2-05, Montreal H3A 1A1, QC, Canada Full list of author information is available at the end of the article include an early degeneration of the cholinergic network, nicotinic neurons in particular, that progressively extends to other types of neurotransmission, neuroinflammation, amyloid plaque deposition, neurofibrillary tangles, and loss of white matter. $\mathrm{AD}$ has become a major healthcare concern. It is expected that the number of patients suffering from $\mathrm{AD}$ in the United States and European Union, currently between 5 and 6 million, will double by 2040. The picture is even darker if we consider that this evaluation only includes the patients who have been or could be diagnosed, not those for whom the disease is still clinically silent, and does not include China and India, where information concerning $\mathrm{AD}$ is limited. The human cost goes well beyond the patients; it also includes the caregivers, with a ratio of three caregivers per patient. The financial cost for society is also exorbitant: US $\$ 200$ billion for the United States in 2012. Current projections estimate an increase to US\$1.1 trillion in 2050. In comparison, the financial stimulus package passed by the Obama administration in 2011 was $\$ 800$ billion.

The history of drug development for $\mathrm{AD}$ is not a success story. For years, drug developers focused on compensating for the loss of cholinergic neurotransmission. This led to the development of acetylcholinesterase inhibitors, with tacrine as the class leader. This strategy was based on the hypothesis that inhibiting the enzyme that degrades acetylcholine (Ach) would restore physiological concentrations of Ach in the synaptic cleft and the functionality of cholinergic neurotransmission, resulting in therapeutic benefit. Tacrine, which was released to the market in the early 1990s, showed some modest activity in clinical trials; however, its therapeutic use was hampered by dramatic liver toxicity, which required close monitoring of patient liver function [1]. Tacrine was progressively replaced by a new generation of acetylcholinesterase inhibitors, namely galantamine, donepezil, and rivastigmine, which were devoid of liver toxicity but produced questionable therapeutic benefits [2]. In 2004, the non-competitive N-methyl-D-aspartate (NMDA) antagonist memantine was released to the market. Although the toxicological profile of memantine was excellent, the therapeutic benefits in AD were modest [3]. Since then, the AD pipeline has suffered numerous 
setbacks due to failed clinical trials of the vaccine AN1792, amyloid peptide ligand/plaque formation inhibitor tramiprozate, $\gamma$-secretase modulator tarenflurbil, $\gamma$ secretase inhibitor LY540139, anti-histamine latrepirdine, and more recently, humanized monoclonal antibodies bapineuzumab and solanezumab. Interestingly, all of these compounds demonstrated significant efficacy in transgenic animal models of AD.

Animal models of disease are a cornerstone of the drug development process. Their function is to closely mimic the disease or an aspect of the disease in humans and translate the results obtained in vitro to clinical applications. The need for animal models of pathologies affecting the central nervous system has been recognized since 1980 [4]. An attempt to establish criteria for such animal models was made the same year [5]. The first tools described as animal models of $\mathrm{AD}$ were based on etiological considerations of the disease, whether chronic aluminum intoxication [6] or excitotoxic lesions of cholinergic neurotransmission [7] was thought to be at the origin of the neurodegeneration. The early 1990s saw the appearance of the first transgenic mouse models of AD, nearly a decade after the discovery of the first mutation in the gene encoding the amyloid precursor protein (APP) and its central role in the familial form of AD. These models, which carried a mutated form of the human APP gene, were found to be unsatisfactory, and double transgenic mice carrying two human mutated transgenes, APP/PS1 [8] or APP/tau, were developed [9]. This was soon followed by the APP/PS1/tau triple transgenic mouse model [10]. The strategy behind the development of these models was to reproduce pathological features observed in $\mathrm{AD}$, including the sporadic form, rather than tackle the etiology of AD. This consideration justified the use of the transgene tauP301L, a mutation of the gene encoding the tau protein that is not encountered in $\mathrm{AD}$ but pertains to the frontotemporal dementia with Parkinsonism linked to chromosome 17.

Although the rat has been the animal of choice for drug development and fundamental research for decades, it progressively faded away in favor of mice, a species in which genetic manipulation is much easier and for which there is a greater variety of research reagents available. These transgenic models contributed tremendously to our understanding of the molecular mechanisms involved in the onset and progression of the disease. Transgenic mouse models of AD helped decipher the secretory pathway of APP and the production of $A \beta_{42}$ through APP cleavage by $\beta$ - and $\gamma$-secretases [11], thus improving our understanding of $\mathrm{AD}$ pathogenesis. In addition, these animal models provided evidence about the physiological role played by APP, APP fragments and $\alpha$-secretase in processes like neurogenesis $[12,13]$ and the mechanism underlying memory consolidation [14].
It is undeniable that transgenic mouse models of $\mathrm{AD}$ led the way of the fundamental research so far conducted on understanding the disease. Moreover, it is critical to mention the primordial role played by the transgenic mouse models in the development of tracers for magnetic resonance imaging (MRI) and positron emission tomography (PET) imaging and in the characterization of new biomarkers $[15,16]$. However, transgenic mouse models have some limitations $[17,18]$. First, unlike the human neuropathology, which displays massive neurodegeneration, only very few models show neuronal death and on a scale that does not compare to what is seen on postmortem human brains. Second, the way the genetic manipulation translates into the histological and clinical recapitulation of the disease highly depends on the promoter used to insert the transgene and on the genetic background of the recipient animal. This actually makes any comparison between transgenic mouse models difficult. And last, but certainly not the least, due to their nature, these models only relate to the familial earlyonset form of AD (FAD), which represents a mere $5 \%$ of AD diagnoses. The remaining 95\% are sporadic late-onset forms (SAD), the causes of which remain elusive.

Although SAD and FAD clinical phenotypes are very similar, SAD does not involve mutations and the cause for amyloid accumulation and aggregation remains to be established. In that sense, transgenic mouse models are unfitted for unveiling SAD etiopathogenesis. In addition, the only true validation of an animal model used for drug development purposes is whether it led to successful testing in human trials and thus to the subsequent release of a drug to the market. From discovery to Food and Drug Administration (FDA) approval for release, it takes an average of 15 years to complete a drug development program. The first transgenic mouse model of $\mathrm{AD}$ was developed 22 years ago. Based on the current condition of the $\mathrm{AD}$ drug pipeline, the limitations of these transgenic models of $\mathrm{AD}$ in drug development are apparent. The obstacles to drug development require creation of novel animal models focusing on the etiology rather than symptomatology of the disease using a pharmacological approach rather than a genetic approach.

In this review, we will discuss the historical genesis of various non-transgenic rat models of $\mathrm{AD}$ that have been established, the re-appearance of the rat as a potential tool for drug development for $\mathrm{AD}$, and how pharmacologically induced rat models may help overcome the challenges of $\mathrm{AD}$ research and drug development.

\section{The genesis and the evolution of AD rat models}

In 1980, WJ Hadlow wrote 'Even though finding an animal model embodying the total picture of senile brain disease with dementia is unlikely, efforts should be made to identify in some animal each of the several aspects of 
the aging process and dementia' [5]. In the early 1980s, the progressive degeneration of cholinergic neurotransmission was thought to be the pathological pathway, if not the origin of $\mathrm{AD}$, and at least a major contributor to the disease. During this decade, consistent with the cholinergic hypothesis and WJ Hadlow's statement, the first animal models of $\mathrm{AD}$ were developed based on impairing central cholinergic function to reproduce the alterations of cognitive performance seen in clinics. A prominent strategy was the use of the choline mustard aziridium AF64A in many cases. AF64A is a chemical that preferentially triggers degeneration of cholinergic neurotransmission. AF64A was used in various protocols, including in situ injection into the dorsal hippocampus [19], the frontal cortex [20], or the nucleus basalis magnocellularis [21] or administration through an intracerebroventricular route [22]. These procedures were primarily aimed at inducing degeneration of the cholinergic neurons in the nucleus basalis magnocellularis. Another strategy consisted of using a glutamatergic agonist to induce the excitotoxic degeneration [23] of a subpopulation of cholinergic neurons. Thus, ibotenic acid [24], an agonist of the NMDA receptor, and kainic acid [25], a kainate receptor agonist, were both used by local injection into the nucleus basalis magnocellularis or in the cortex to induce a deficit in cholinergic neurotransmission. More anecdotic were the injection of diphtheria toxin into the nucleus basalis magnocellularis [26] or the grafting of $\mathrm{AD}$ patient brain tissue into the rat occipital cortex [27]. In addition to histological traits similar to those described in AD patients, these cholinergic-based rat models commonly displayed memory deficits and learning impairment.

The 1990s saw a downturn in the development of rat models, as they became progressively overshadowed by the emerging transgenic mouse models of $\mathrm{AD}$. These transgenic mice became the dominant animal models for fundamental research and drug discovery in the field of AD. However, the emphasis on the nicotinic receptor as a target for $\mathrm{AD}$ [28] encouraged the use of the wellcharacterized cholinergic-based rat models for nicotine and nicotine derivative drug development programs [29]. Although the transgenic models were taking over the field of in vivo experimentation in $\mathrm{AD}$, rats were still considered a useful model organism for development of AD models. The 1990s saw the beginning of a shift toward animal models reflecting the hypothesis that amyloidogenesis underlies the disease. As previously mentioned, the deposition of amyloid plaques in brain parenchyma is a hallmark of $\mathrm{AD}$. An attempt to reproduce this histological alteration was conducted in rats for the first time by Frautschy and colleagues in 1992 by injecting purified amyloid plaques extracted from human $\mathrm{AD}$ brains into the cortex and hippocampus of adult rats [30]. This resulted in plaque formation and vascular amyloidogenesis in the rat brain. This first attempt paved the way for a new generation of rat models of AD. Two years later, Ingram and colleagues [31], who clearly identified the need to go beyond the cholinergic hypothesis to establish other animal models that would help answer questions pertaining to $\mathrm{AD}$ not strictly related to cholinergic neurotransmission, advocated the use of such models. In the meantime, efforts were still made to refine cholinergic-based rat models using 192 IgG-saporin, a toxin linked to an immunoglobulin that selectively targets cholinergic neurons [32].

The shift initiated in the 1990s took full shape during the next decade, when most of the rat models developed reflected the attempt to reproduce the amyloidogenic cascade and related amyloid peptide pathological pathways. The general principle was to inject a form of amyloid peptide into the rat brain so the animal would develop one or several of the pathological features documented in clinics. Various forms of the amyloid peptide $(A \beta)$ were used in acute injection or chronic infusion. $A \beta_{1-40}[33,34]$ and $A \beta_{1-42}[35,36]$ were most commonly used either by intracerebroventricular infusion or by intrahippocampal injection. These peptides were used as the sole disease-triggering agents, with the exception of the ferrous amyloid buthionine (FAB) rat [35], a rat model in which the $\mathrm{AD}$ phenotype is induced by the infusion of a solution containing the amyloid peptide $\mathrm{A} \beta_{1-42}$, the inhibitor of glutathione synthesis buthionine sulfoximine, and ferrous sulfate over 4 weeks. We will discuss the FAB rat in more detail below.

Other amyloid species used included $A \beta_{25-35}$ [37], a neurotoxic non-amyloidogenic fragment, and $A \beta_{1-43}$ [34]. These various amyloid fragments did not induce similar pathological phenotypes. While histological alterations similar to those seen in AD patients were consistently found in most of the models (although the exact histopathology varied from one to another), reproducing the decline of cognitive performance was highly dependent on the experimental protocol. The amyloid peptide infusion site and regimen used were of particular importance. Another strategy developed during this decade was based on the hypothesis that AD may be a type 3 diabetes [38]. This hypothesis was based on post-mortem histological observations of the brains of AD patients, which showed a consistent decrease in expression of insulin, insulin-like growth factor, and their corresponding receptors [38]. It was then assumed that injecting streptozotocin, a glucosaminenitrosourea toxic to pancreatic $\beta$ cells, into rat brain would result in the same pattern. Streptozotocin administration induced the phosphorylation of the tau protein, amyloid deposits, cognitive impairment, insulin desensitization, and neuronal death $[39,40]$. 
The beginning of the current decade saw an increasing number of preclinical studies using $\mathrm{AD}$ rat models characterized during the 2000s to implement drug development programs. In particular, rat models faithfully reproducing amyloid pathogenesis were used to assess the efficacy of drug candidates as diverse as steroid analogs [41-43], fatty acids [44], polyphenols [45], nonsteroidal anti-inflammatory drugs [44], plant extracts $[46,47], \gamma$-secretase inhibitor [48], stem cell proliferative agents [49], naturally occurring compounds [43,50,51], and plaque formation inhibitors [52]. Other than the type of amyloid peptide used in these models, a major difference was the injection regimen into the brain. The solution containing the amyloid peptide was administered either by chronic infusion or locally in a very specific part of the brain, mainly the hippocampus $[41,42,47,49]$. Intra-amygdala injection [52] or acute intracerebroventricular injection [46,50,52] have also been reported. Chronic infusion was achieved through intracerebroventricular administration using an Alzet $^{\odot}$ type of osmotic micropump, generally over a 2- to 4-week period of time $[43-45,48]$. The resurgence of interest in the rat as an animal model of AD led other investigators to use various other types of rat models to investigate the effect of molecules of potential therapeutic interest. These models included, but were not restricted to, specific cholinergic deficits [53], streptozotocin injections $[54,55]$, okadaic acid-induced tau protein hyperphosphorylation [56], and aluminum salt administration [57].

This combination of circumstances during the past decade, including the failure of transgenic models to fulfill expectations and an increased diversity of experimental reagents, redefined the rat as a very useful tool to develop new models of AD. In the next section, we will focus on a particular AD rat model we developed in our laboratory that is used by us and others in drug development programs.

\section{The ferrous amyloid buthionine (FAB) rat model}

The FAB rat was developed in response to our need to have available an animal model of $\mathrm{AD}$ that corresponds to the sporadic form of the disease. The choice of the rat strain was made carefully so that it would contribute to the development of the model. Long-Evans rats were selected for these studies because of their high susceptibility to neurodegenerative diseases. Indeed, the Long-Evans strain carries a mutation of the Cblb gene that has been demonstrated to render the encoded protein inactive, and Cblb-deficient mouse strains are highly sensitive to experimental encephalomyelitis after immunization with myelin basic protein [58]. Because the rodent protein is $96 \%$ homologous with the human protein, findings from this rat strain are extremely pertinent to human neurodegenerative diseases [59]. The
Long-Evans strain also possessed another advantage: they are not albino rats and therefore do not have the impaired sight of albino strains. Indeed, impaired sight was a factor that we identified as a potential problem when animals would be involved in cue recognitionrelated experiments (for example, a water maze) in which the distance between the animal and the cues may exceed vision capacity.

The AD phenotype was induced by administering a solution containing the human form of the 42-residue amyloid peptide $\left(A \beta_{1-42}\right)$, ferrous sulfate, and buthionine sulfoximine via the intracerebroventricular route over a period of 4 weeks [35]. A $\beta_{1-42}$ was chosen because of its superior aggregating properties and because, at that time, it was thought to constitute the nucleus of any amyloid plaque formation. Ferrous sulfate was added to the solution as a pro-oxidative agent known to trigger oxidative stress through the Fenton reaction and induce the oxidation of various components of the cell membrane and subcellular compartments. In addition, the presence of iron deposits was described in amyloid plaques observed post-mortem in patients' brain tissue. Buthionine sulfoximine, an inhibitor of glutathione synthesis, was used to reduce the natural antioxidant defense of the brain and facilitate oxidative stress. Oxidative stress is a deleterious process that, since the late 1980 s to early 1990s [61-63], has been unanimously recognized to play a role in AD pathogenesis [60]. It is generally admitted that oxidative species are generated either from, but not restricted to, neuroinflammation, mitochondria respiratory chain impairment $[64,65]$ or from a direct effect of the amyloid peptide [66]. Many compounds are currently being developed aiming at the oxidative pathway as a potential treatment for the disease and oxidative profiling has gained interest as a biomarker of disease progression and for diagnostics purposes [67], and in this regard, the FAB rat may constitute an interesting model to test these approaches in preclinical development.

The solution was infused in the left ventricle using an Alzet $^{\oplus}$ 2ML4 osmotic micropump. Four weeks of infusion resulted in the appearance of an $\mathrm{AD}$ phenotype that included cognitive impairment and development of a related histopathology [35]. The animals displayed significant impairment of spatial memory as measured in a Morris water maze task. Histological alterations included amyloid plaque deposits in the hippocampus and cortex, hyperphosphorylated tau protein, and formation of neurofibrillary tangles. Hyperphosphorylated tau protein was evidenced by positive immunoreactivity to Ser-199/202 and to Thr-181 epitopes [68,69] using AT-8 and AT-270 monoclonal antibodies, respectively [43]. Phosphorylated Ser-199/202 and Thr-181 are biomarkers commonly used in the clinic to measure hyperphosphorylated tau levels in the cerebrospinal fluid of $\mathrm{AD}$ 
patients $[69,70]$. However, the exact subcellular localization of the neuronal hyperphosphorylated tau protein has not yet been determined. Neurodegeneration occurring in the cortex and hippocampus, neuroinflammation in the form of intense astrogliosis and microgliosis, and DNA oxidation were also reported. In addition, vascular amyloidosis was also observed. The AD phenotype developed only when the three components of the FAB solution were used together. No histopathological features or alterations of cognitive performance occurred when the amyloid peptide was used alone or in combination with only one of the other two compounds, highlighting the key role played by oxidative stress in amyloid peptide pathogenesis. Although others reported the occurrence of an $\mathrm{AD}$-like phenotype after injection of amyloid as a sole pathological agent, this disparity may be explained by differences between rat strains. The neuronal phenotype vulnerability exhibited by these animals remains to be determined and at present this represents a limitation of this particular model.

Since then, the FAB model has been the centerpiece of our drug development programs. In particular, it successfully contributed to the characterization of the anti-AD properties of caprospinol, a naturally occurring steroid analog $[43,71,72]$ for which an investigational new drug application has been submitted to the FDA. The FAB model has been reproduced by others and was recently commercialized by Taconic Farms, Inc. [73-76]. A summary of the experimental protocol used to develop the FAB model, the phenotype obtained as well as the effect of caprospinol on the FAB phenotype are outlined in Figure 1.

\section{The transgenic rat models of Alzheimer's disease}

Increasing knowledge in molecular biology allowed overcoming the complexity to undertake transgenesis studies in the rat. The concept applied was identical to the one used to develop transgenic mice and relied on the expression of one or several mutated human genes involved in the familial form of $\mathrm{AD}$. One can argue that transgenic rats may not offer more interest than the transgenic mice available considering that they only represent another transgenic rodent model for the familial form of $\mathrm{AD}$. In addition, the generated transgenic rats only reflect the amyloidogenesis hypothesis of Alzheimer's physiopathology. On the other hand, rats have always been regarded as a more robust tool for cognitive assessment, being capable, unlike mice but like primates, of higher order cognitive processes like metacognition. In that sense, rats are capable of cognitive processes at a higher level compared to mice, closing further the gap with humans. The first AD transgenic rat was produced in 2004 and carried the human APPswe mutated gene [77]. This model did not display any of the known AD histological alteration and, surprisingly, performed better in cognitive tasks than the age-matched control animals. Transgenic rat models developed thereafter included McGill-R-Thy1-APP [78], UKUR25 [79], Tg6590 [80], Tg478 [81], Tg1116 [81], Tg11587 [82], APP21 [83] and APP31 [83]. These models were built on various backgrounds, Sprague-Dawley, Wistar and Fisher-344, using various gene promoters like PDGF, murine Thy-1, synapsin-1 or ubiquitin-C. They all carry one or several mutations of the human APP transgene. Not all the models display histological modifications or cognitive impairment, and as for most of the mice models, there is no correlation between reduced cognitive performance and brain tissue histological alteration.

Similarly to mice, rats were used to mimic the tauopathy seen in AD. A major difference is that instead of using a human mutated transgene that is not relevant to the disease, rats express a truncated form of the normal human tau protein. These models displayed cognitive impairment associated to hyperphosphorylated tau protein and formation of tangles [84-86]. However, none of them show any sign of neuronal death $[84,86]$.

Few rat models were developed using viral vectors. Adenoviral-associated viral vectors were locally injected in the hippocampus of Wistar rats to express a transgene encoding the fusion protein $\mathrm{BRI}-\mathrm{A} \beta_{42}$ or BRI-A $\beta_{40}[87,88]$. Animals co-transfected with both BRI-A $\beta_{42}$ and BRI-A $\beta_{40}$ displayed a mild cognitive impairment. In these animals plaque formation in the brain was observed only in rats expressing BRI-A $\beta_{42}$ alone. In addition, no pathological alterations of the brain histology were reported. One possible explanation could be found in the nature of the transgene itself. Mutation of the BRI gene results in the expression of the amyloid protein ABri and is linked to familial British dementia [89]. ABri precursor is cleaved by furin and furin-like proteases in order to release the peptide. However, ABri is not a substrate for the carboxypeptidase secretases that process APP. Likewise, the fusion protein undergoes furin-controlled cleavage, and unlike APP, does not follow the carboxypeptidase secretory pathway to release $A \beta_{42}$ [87]. Such a 'hybrid' metabolic pathway may lead to the mild pathological profile described and raise questions about the capacity of the model to reproduce, at least in part, the $\mathrm{AD}$ phenotype. Another approach consisted in using a lentivirus-based vector to transfect the parkin-A $\beta_{42}$ transgene [90] in the motor cortex of Sprague-Dawley rats [91]. The treated animals exhibited intraneuronal amyloidosis, Tau protein hyperphosphorylation and neuronal death. However, a major limitation of this model is the lack of cognitive impairment due to the site chosen by the investigators to inject the lentiviral construct. Indeed, no alteration of the motor cortex, an area not primarily affected in $\mathrm{AD}$, would affect cognitive 


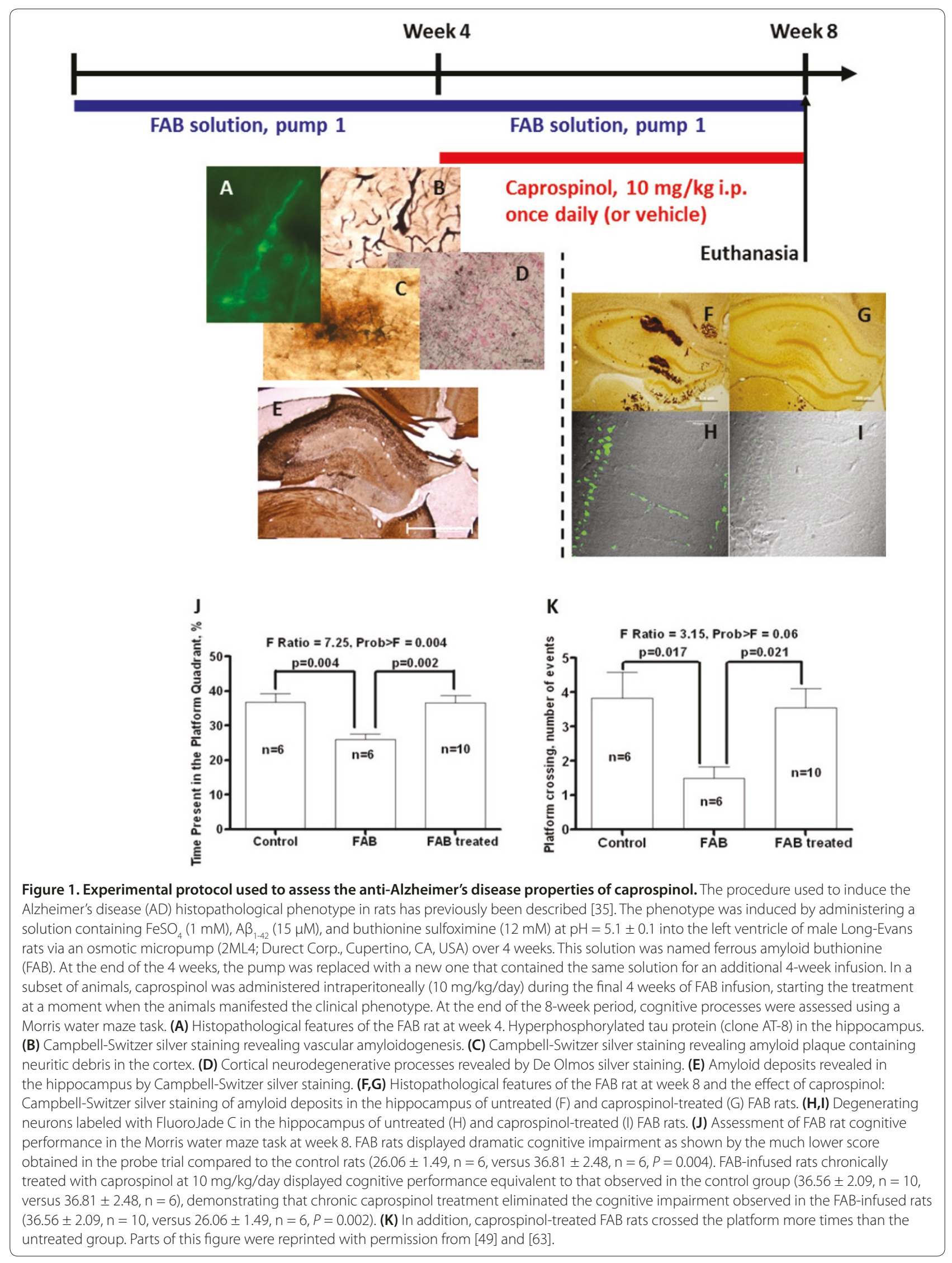


performances, and this should be regarded as a major setback.

\section{Conclusion}

$\mathrm{AD}$ is a devastating disease that takes a tremendous toll on western societies and beyond. Unfortunately, despite decades of effort and billions of dollars spent, no real treatment has been brought to the market. However, all of the drug candidates that failed in clinical trials showed anti-AD activity in various transgenic animal models. Until recently, drug development research programs exclusively used transgenic mouse models to assess the properties of drug candidates. Transgenic models still represent the golden standard. However, if we consider contributions to drug development and release to the market the ultimate validation of an animal model, we must admit that there is room for different types of animal models. It is especially crucial to stress that rat and mouse transgenic models of $\mathrm{AD}$ address only the familial form of the disease, which barely represents $5 \%$ of $\mathrm{AD}$ cases. We discussed the potential of pharmacologically induced rat models of $\mathrm{AD}$, which are more relevant to the sporadic form of $A D$, the $F A B$ rat in particular, and the increasing role they may play in the current drug development for AD effort. Indeed, because these models represent the sporadic form of $\mathrm{AD}$, they may, if successful, change the regulatory framework needed to proceed to $\mathrm{AD}$ trials and bring value to clinical trial design. The rat, despite been the most widely used animal model in pharmacological and toxicological studies, has long been neglected as a tool for drug discovery in the field of AD. A better understanding of rat strains, an increasing variety of available reagents specific to the rat, and the understanding that there is an urgent need for a model relevant to the most frequent form of AD may lead to a new era of animal models that drive future successful drug development.

\section{Abbreviations}

$A \beta$, amyloid peptide; Ach, acetylcholine; AD, Alzheimer's disease; APP, amyloid precursor protein; $F A B$, ferrous amyloid buthionine; $F A D$, familial early-onset form of Alzheimer's disease; FDA, Food and Drug Administration; NMDA, $\mathrm{N}$-methyl-D-aspartate; PS1, presenilin-1; SAD, sporadic late-onset form of Alzheimer's disease.

\section{Competing interests}

The authors declare that they have no competing interests.

\section{Acknowledgments}

Preparation of this review was supported by a Canada Research Chair in Biochemical Pharmacology (VP) and the Research Institute of the MUHC, which is supported by a Center grant from Le Fonds de la Recherche du Québec-Santé.

\section{Author details}

'The Research Institute of the McGill University Health Centre, Royal Victoria Hospital, 687 Pine avenue West, room L2-05, Montreal H3A 1A1, QC, Canada. ${ }^{2}$ Department of Medicine, McGill University, Royal Victoria Hospital, 687 Pine avenue West, room L2-05, Montreal H3A 1A1, QC, Canada. ${ }^{3}$ Departments of
Biochemistry and Pharmacology and Therapeutics, McGill University, McIntyre Medical Sciences Bldg, 3655 Promenade Sir-William-Osler, room 1325, Montreal Quebec, Canada H3G 1 Y6.

Published: 1 May 2013

\section{References}

1. Chatellier G, Lacomblez L: Tacrine (tetrahydroaminoacridine; THA) and lecithin in senile dementia of the Alzheimer type: a multicentre trial. Groupe Francais d'Etude de la Tetrahydroaminoacridine. BMJ 1990, 300:495-499.

2. Kaduszkiewicz H, Zimmermann T, Beck-Bornholdt HP, van den Bussche H: Cholinesterase inhibitors for patients with Alzheimer's disease: systematic review of randomised clinical trials. BMJ 2005, 331:321-327.

3. Areosa SA, Sherrifff, McShane R: Memantine for dementia. Cochrane Database Syst Rev 2005:CD003154.

4. Vogel FS: Needs for animal models of human diseases of the nervous system. Am J Pathol 1980, 101:S201-S211.

5. Hadlow WJ: Criteria for development of animal models of diseases of the nervous system. Am J Pathol 1980, 101:S213-S219.

6. Rabe A, Lee MH, Shek J, Wisniewski HM: Learning deficit in immature rabbits with aluminum-induced neurofibrillary changes. Exp Neurol 1982, 76:441-446.

7. Ksir C, Benson DM: Enhanced behavioral response to nicotine in an animal model of Alzheimer's disease. Psychopharmacology (Berl) 1983, 81:272-273.

8. Borchelt DR, Ratovitski T, van L, Lee MK, Gonzales V, Jenkins NA, Copeland NG, Price DL, Sisodia SS: Accelerated amyloid deposition in the brains of transgenic mice coexpressing mutant presenilin 1 and amyloid precursor proteins. Neuron 1997, 19:939-945.

9. Lewis J, Dickson DW, Lin WL, Chisholm L, Corral A, Jones G, Yen SH, Sahara N, Skipper L, Yager D, Eckman C, Hardy J, Hutton M, McGowan E: Enhanced neurofibrillary degeneration in transgenic mice expressing mutant tau and APP. Science 2001, 293:1487-1491.

10. Oddo S, Caccamo A, Shepherd JD, Murphy MP, Golde TE, Kayed R, Metherate R, Mattson MP, Akbari Y, LaFerla FM: Triple-transgenic model of Alzheimer's disease with plaques and tangles: intracellular Abeta and synaptic dysfunction. Neuron 2003, 39:409-421

11. Lannfelt L, Folkesson R, Mohammed AH, Winblad B, Hellgren D, Duff K, Hardy J: Alzheimer's disease: molecular genetics and transgenic animal models. Behav Brain Res 1993, 57:207-213.

12. Lazarov O, Marr RA: Neurogenesis and Alzheimer's disease: at the crossroads. Exp Neurol 2010, 223:267-281.

13. Zhou ZD, Chan CH, Ma QH, Xu XH, Xiao ZC, Tan EK: The roles of amyloid precursor protein (APP) in neurogenesis: Implications to pathogenesis and therapy of Alzheimer disease. Cell Adh Migr 2011, 5:280-292.

14. Korte M, Herrmann U, Zhang X, Draguhn A: The role of APP and APLP for synaptic transmission, plasticity, and network function: lessons from genetic mouse models. Exp Brain Res 2012, 217:435-440.

15. Platt B, Welch A, Riedel G: FDG-PET imaging, EEG and sleep phenotypes as translational biomarkers for research in Alzheimer's disease. Biochem Soc Trans 2011, 39:874-880.

16. Teipel SJ, Buchert R, Thome J, Hampel H, Pahnke J: Development of Alzheimer-disease neuroimaging-biomarkers using mouse models with amyloid-precursor protein-transgene expression. Prog Neurobiol 2011, 95:547-556.

17. Balducci C, Forloni G: APP transgenic mice: their use and limitations. Neuromol Med 2011, 13:117-137.

18. Braidy N, Munoz P, Palacios AG, Castellano-Gonzalez G, Inestrosa NC, Chung RS, Sachdev P, Guillemin GJ: Recent rodent models for Alzheimer's disease: clinical implications and basic research. J Neural Transm 2012, 119:173-195.

19. Colhoun EH, Myles LA, Rylett RJ: An attempt to produce cholinergic hypofunction in rat brain using choline mustard aziridinium ion: neurochemical and histological parameters. Can J Neurol Sci 1986, 13:517-520.

20. Stephens PH, Tagari P, Cuello AC: Ethylcholine mustard aziridinium ion lesions of the rat cortex result in retrograde degeneration of basal forebrain cholinergic neurons: implications for animal models of neurodegenerative disease. Neurochem Res 1987, 12:613-618.

21. Pepeu G, Casamenti F, Pedata F, Cosi C, Pepeu IM: Are the neurochemical and behavioral changes induced by lesions of the nucleus basalis in the rat a model of Alzheimer's disease? Prog Neuropsychopharmacol Biol 
Psychiatry 1986, 10:541-551.

22. Nakahara N, Iga Y, Mizobe F, Kawanishi G: Effects of intracerebroventricular injection of AF64A on learning behaviors in rats. Jpn J Pharmacol 1988, 48:121-130.

23. Olney JW, Adamo NJ, Ratner A: Monosodium glutamate effects. Science 1971, 172:294

24. Fine A, Dunnett SB, Bjorklund A, Iversen SD: Cholinergic ventral forebrain grafts into the neocortex improve passive avoidance memory in a rat model of Alzheimer disease. Proc Natl Acad Sci U S A 1985, 82:5227-5230.

25. Friedman E, Lerer B, Kuster J: Loss of cholinergic neurons in the rat neocortex produces deficits in passive avoidance learning. Pharmacol Biochem Behav 1983, 19:309-312.

26. Kudo Y, Shiosaka S, Matsuda M, Tohyama M: An attempt to cause the selective loss of the cholinergic neurons in the basal forebrain of the rat: a new animal model of Alzheimer's disease. Neurosci Lett 1989, 102:125-130.

27. van den Bosch de Aguilar, Langhendries-Weverberg C, Goemaere-Vanneste J, Flament-Durand J, Brion JP, Couck AM: Transplantation of human cortex with Alzheimer's disease into rat occipital cortex; a model for the study of Alzheimer disease. Experientia 1984, 40:402-403.

28. Jones G, Levy R, Sahakian B: Nicotine and Alzheimer's disease. Br J Psychiatry $1990,156: 280-281$

29. Decker MW, Brioni JD, Sullivan JP, Buckley MJ, Radek RJ, Raszkiewicz JL, Kang CH, Kim DJ, Giardina WJ, Wasicak JT, et al:: (S)-3-methyl-5-(1-methyl-2pyrrolidinyl)isoxazole (ABT 418): a novel cholinergic ligand with cognitionenhancing and anxiolytic activities: II. In vivo characterization. J Pharmacol Exp Ther 1994, 270:319-328.

30. Frautschy SA, Cole GM, Baird A: Phagocytosis and deposition of vascular beta-amyloid in rat brains injected with Alzheimer beta-amyloid. Am J Pathol 1992, 140:1389-1399.

31. Ingram DK, Spangler EL, lijima S, Ikari H, Kuo H, Greig NH, London ED: Rodent models of memory dysfunction in Alzheimer's disease and normal aging: moving beyond the cholinergic hypothesis. Life Sci 1994, 55:2037-2049.

32. Schliebs R, Rossner S, Big IV: Immunolesion by 192lgG-saporin of rat basal forebrain cholinergic system: a useful tool to produce cortical cholinergic dysfunction. Prog Brain Res 1996, 109:253-264

33. Malin DH, Crothers MK, Lake JR, Goyarzu P, Plotner RE, Garcia SA, Spell SH, Tomsic BJ, Giordano T, Kowall NW: Hippocampal injections of amyloid betapeptide 1-40 impair subsequent one-trial/day reward learning. Neurobiol Learn Mem 2001, 76:125-137.

34. Stephan A, Laroche S, Davis S: Generation of aggregated beta-amyloid in the rat hippocampus impairs synaptic transmission and plasticity and causes memory deficits. J Neurosci 2001, 21:5703-5714.

35. Lecanu L, Greeson J, Papadopoulos V: Beta-amyloid and oxidative stress jointly induce neuronal death, amyloid deposits, gliosis, and memory impairment in the rat brain. Pharmacology 2006, 76:19-33.

36. Nakamura S, Murayama N, Noshita T, Annoura H, Ohno T: Progressive brain dysfunction following intracerebroventricular infusion of beta(1-42)amyloid peptide. Brain Res 2001, 912:128-136.

37. Arif M, Chikuma T, Ahmed MM, Nakazato M, Smith MA, Kato T: Effects of memantine on soluble Alphabeta(25-35)-induced changes in peptidergic and glial cells in Alzheimer's disease model rat brain regions. Neuroscience 2009, 164:1199-1209.

38. Pilcher H: Alzheimer's disease could be "type 3 diabetes". Lancet Neurol 2006, 5:388-389

39. de la Monte SM, Tong M: Mechanisms of nitrosamine-mediated neurodegeneration: potential relevance to sporadic Alzheimer's disease. J Alzheimers Dis 2009, 17:817-825.

40. Grunblatt E, Hoyer S, Riederer P: Gene expression profile in streptozotocin rat model for sporadic Alzheimer's disease. J Neural Transm 2004, 111:367-386.

41. Bagheri M, Joghataei MT, Mohseni S, Roghani M: Genistein ameliorates learning and memory deficits in amyloid beta(1-40) rat model of Alzheimer's disease. Neurobiol Learn Mem 2011, 95:270-276.

42. Limon D, Diaz A, Hernandez M, Fernandez G, Torres-Martinez AC, PerezSeveriano F, Rendon-Huerta EP, Montano LF, Guevara J: Neuroprotective effect of the aminoestrogen prolame against impairment of learning and memory skills in rats injected with amyloid-beta(-)(2)(5)(-)(3)(5) into the hippocampus. Eur J Pharmacol 2012, 685:74-80.

43. Lecanu L, Rammouz G, McCourty A, Sidahmed EK, Greeson J, Papadopoulos $\mathrm{V}$ : Caprospinol reduces amyloid deposits and improves cognitive function in a rat model of Alzheimer's disease. Neuroscience 2010, 165:427-435.

44. Di SA, Sozio P, Cerasa LS, lannitelli A, Cataldi A, Zara S, Giorgioni G, Nasuti C Ibuprofen and lipoic acid diamide as co-drug with neuroprotective activity: pharmacological properties and effects in beta-amyloid (1-40) infused Alzheimer's disease rat model. Int I Immunopathol Pharmacol 2010 23:589-599.

45. Ahmed T, Gilani AH: A comparative study of curcuminoids to measure thei effect on inflammatory and apoptotic gene expression in an Abeta plus ibotenic acid-infused rat model of Alzheimer's disease. Brain Res 2011, 1400:1-18

46. Kashani MS, Tavirani MR, Talaei SA, Salami M: Aqueous extract of lavender (Lavandula angustifolia) improves the spatial performance of a rat model of Alzheimer's disease. Neurosci Bull 2011, 27:99-106.

47. Li X, Yuan HF, Quan QK, Wang JJ, Wang NN, Li M: Scavenging effect of Naoerkang on amyloid beta-peptide deposition in the hippocampus in a rat model of Alzheimer's disease. Chin J Integr Med 2011, 17:847-853.

48. Alkadhi KA, Alzoubi KH, Srivareerat M, Tran TT: Elevation of BACE in an Abeta rat model of Alzheimer's disease: exacerbation by chronic stress and prevention by nicotine. Int J Neuropsychopharmacol 2012, 15:223-233.

49. Han M, Liu Y, Tan Q, Zhang B, Wang W, Liu J, Zhang XJ, Wang YY, Zhang JM: Therapeutic efficacy of stemazole in a beta-amyloid injection rat model of Alzheimer's disease. Eur J Pharmacol 2011, 657:104-110.

50. Wang Y, Liu J, Zhang Z, Bi P, Qi Z, Zhang C: Anti-neuroinflammation effect of ginsenoside Rbl in a rat model of Alzheimer disease. Neurosci Lett 2011, 487:70-72.

51. Zhou J, Zhou L, Hou D, Tang J, Sun J, Bondy SC: Paeonol increases levels of cortical cytochrome oxidase and vascular actin and improves behavior in a rat model of Alzheimer's disease. Brain Res 2011, 1388:141-147

52. Hatip FF, Hatip-Al-Khatib I, Matsunaga Y, Suenaga M, Sen N: Effects of 8-residue beta sheet breaker peptides on aged Abeta40-induced memory impairment and Abeta40 expression in rat brain and serum following intraamygdaloid injection. Curr Alzheimer Res 2010, 7:602-614.

53. Gelfo F, Tirassa P, De BP, Caltagirone C, Petrosini L, Angelucci F: Brain and serum levels of nerve growth factor in a rat model of Alzheimer's disease. J Alzheimers Dis 2011, 25:213-217.

54. Salkovic-Petrisic M, Tribl F, Schmidt M, Hoyer S, Riederer P: Alzheimer-like changes in protein kinase $B$ and glycogen synthase kinase- 3 in rat frontal cortex and hippocampus after damage to the insulin signalling pathway. J Neurochem 2006, 96:1005-1015.

55. Salkovic-Petrisic M, Osmanovic-Barilar J, Bruckner MK, Hoyer S, Arendt T, Riederer $\mathrm{P}$ : Cerebral amyloid angiopathy in streptozotocin rat model of sporadic Alzheimer's disease: a long-term follow up study. J Neural Transm 2011, 118:765-772

56. Lim YW, Yoon SY, Choi JE, Kim SM, Lee HS, Choe H, Lee SC, Kim DH: Maintained activity of glycogen synthase kinase-3beta despite of its phosphorylation at serine-9 in okadaic acid-induced neurodegenerative model. Biochem Biophys Res Commun 2010, 395:207-212

57. Aly HF, Metwally FM, Ahmed HH: Neuroprotective effects of dehydroepiandrosterone (DHEA) in rat model of Alzheimer's disease. Acto Biochim Pol 2011, 58:513-520.

58. Chiang YJ, Kole HK, Brown K, Naramura M, Fukuhara S, Hu RJ, Jang IK, Gutkind JS, Shevach E, Gu H: Cbl-b regulates the CD28 dependence of T-cell activation. Nature 2000, 403:216-220.

59. Yokoi N, Komeda K, Wang HY, Yano H, Kitada K, Saitoh Y, Seino Y, Yasuda K, Serikawa T, Seino S: Cblb is a major susceptibility gene for rat type 1 diabetes mellitus. Nat Genet 2002, 31:391-394.

60. Zito G, Polimanti R, Panetta V, Ventriglia M, Salustri C, Siotto MC, Moffa F, Altamura C, Vernieri F, Lupoi D, Cassetta E, Rossini PM, Squitti R: Antioxidant status and APOE genotype as susceptibility factors for neurodegeneration in Alzheimer's disease and vascular dementia. Rejuvenation Res 2013, 16:51-56.

61. Gotz ME, Kunig G, Riederer P, Youdim MB: Oxidative stress: free radical production in neural degeneration. Pharmacol Ther 1994, 63:37-122.

62. Gutteridge JM: Hydroxyl radicals, iron, oxidative stress, and neurodegeneration. Ann N Y Acad Sci 1994, 738:201-213.

63. Martins RN, Harper CG, Stokes GB, Masters CL: Increased cerebral glucose-6phosphate dehydrogenase activity in Alzheimer's disease may reflect oxidative stress. J Neurochem 1986, 46:1042-1045.

64. Sochocka M, Koutsouraki ES, Gasiorowski K, Leszek J: Vascular oxidative stress and mitochondrial failure in the pathobiology of Alzheimer's disease: new approach to therapy. CNS Neurol Disord Drug Targets 2013 
[Epub ahead of print].

65. Yan MH, Wang X, Zhu X: Mitochondrial defects and oxidative stress in Alzheimer disease and Parkinson disease. Free Radic Biol Med 2012, pii:S0891-5849(12)01823-0.

66. Butterfield DA, Swomley AM, Sultana R: Amyloid beta-peptide (1-42)-induced oxidative stress in Alzheimer disease: importance in disease pathogenesis and progression. Antioxid Redox Signal 2013 [Epub ahead of print].

67. Fagan AM, Perrin RJ: Upcoming candidate cerebrospinal fluid biomarkers of Alzheimer's disease. Biomark Med 2012, 6:455-476.

68. Goedert M, Jakes R, Crowther RA, Cohen P, Vanmechelen E, Vandermeeren M, Cras P: Epitope mapping of monoclonal antibodies to the paired helical filaments of Alzheimer's disease: identification of phosphorylation sites in tau protein. Biochem J 1994, 301:871-877.

69. Vandermeeren M, Mercken M, Vanmechelen E, Six J, van d, V, Martin JJ, Cras P: Detection of tau proteins in normal and Alzheimer's disease cerebrospinal fluid with a sensitive sandwich enzyme-linked immunosorbent assay. J Neurochem 1993, 61:1828-1834.

70. Parnetti L, Lanari A, Amici S, Gallai V, Vanmechelen E, Hulstaert F: CSF phosphorylated tau is a possible marker for discriminating Alzheimer's disease from dementia with Lewy bodies. Phospho-Tau International Study Group. Neurol Sci 2001, 22:77-78.

71. Papadopoulos V, Lecanu L: Caprospinol: discovery of a steroid drug candidate to treat Alzheimer's disease based on 22R-hydroxycholesterol structure and properties. J Neuroendocrinol 2012, 24:93-101.

72. Lecanu L, Tillement L, Rammouz G, Tillement JP, Greeson J, Papadopoulos V: Caprospinol: moving from a neuroactive steroid to a neurotropic drug. Expert Opin Investig Drugs 2009, 18:265-276.

73. Amijee H, Scopes Dl: The quest for small molecules as amyloid inhibiting therapies for Alzheimer's disease. J Alzheimers Dis 2009, 17:33-47.

74. Cai Z, Zhao B, Ratka A: Oxidative stress and beta-amyloid protein in Alzheimer's disease. Neuromol Med 2011, 13:223-250.

75. Gupta S, Garg GR, Bharal N, Mediratta PK, Banerjee BD, Sharma KK: Reversal of propoxur-induced impairment of step-down passive avoidance, transfer latency and oxidative stress by piracetam and ascorbic acid in rats. Environ Toxicol Pharmacol 2009, 28:403-408.

76. Samaritan Alzheimer's Rat Model ${ }^{\mathrm{Tm}}$ [http://www.taconic.com/user-assets/ Documents/Surgery_Samaritan.pdf]

77. Ruiz-Opazo N, Kosik KS, Lopez LV, Bagamasbad P, Ponce LR, Herrera VL: Attenuated hippocampus-dependent learning and memory decline in transgenic TgAPPswe Fischer-344 rats. Mol Med 2004, 10:36-44.

78. Leon WC Canneva F, Partridge V Allard S, Ferretti MT, DeWilde A, Vercauteren F, Atifeh R, Ducatenzeiler A, Klein W, Szyf M, Alhonen L, Cuello AC: A novel transgenic rat model with a full Alzheimer's-like amyloid pathology displays pre-plaque intracellular amyloid-beta-associated cognitive impairment. J Alzheimers Dis 2010, 20:113-126.

79. Echeverria V, Ducatenzeiler A, Alhonen L, Janne J, Grant SM, Wandosell F, Muro A, Baralle F, Li H, Duff K, Szyf M, Cuello A: Rat transgenic models with a phenotype of intracellular Abeta accumulation in hippocampus and cortex. J Alzheimers Dis 2004, 6:209-219.
80. Kloskowska E, Pham TM, Nilsson T, Zhu S, Oberg J, Codita A, Pedersen LA Pedersen JT, Malkiewicz K, Winblad B, Folkesson R, Benedikz E: Cognitive impairment in the Tg6590 transgenic rat model of Alzheimer's disease. $J$ Cell Mol Med 2010, 14:1816-1823.

81. Flood DG, Lin YG, Lang DM, Trusko SP, Hirsch JD, Savage MJ, Scott RW, Howland DS: A transgenic rat model of Alzheimer's disease with extracellular Abeta deposition. Neurobiol Aging 2009, 30:1078-1090.

82. Liu L, Orozco IJ, Planel E, Wen Y, Bretteville A, Krishnamurthy P, Wang L, Herman M, Figueroa H, Yu WH, Arancio O, Duff K: A transgenic rat that develops Alzheimer's disease-like amyloid pathology, deficits in synaptic plasticity and cognitive impairment. Neurobiol Dis 2008, 31:46-57.

83. Agca C, Fritz JJ, Walker LC, Levey Al, Chan AW, Lah JJ, Agca Y: Development of transgenic rats producing human beta-amyloid precursor protein as a model for Alzheimer's disease: transgene and endogenous APP genes are regulated tissue-specifically. BMC Neurosci 2008, 9:28.

84. Hrnkova M, Zilka N, Minichova Z, Koson P, Novak M: Neurodegeneration caused by expression of human truncated tau leads to progressive neurobehavioural impairment in transgenic rats. Brain Res 2007, 1130:206-213

85. Koson P, Zilka N, Kovac A, Kovacech B, Korenova M, Filipcik P, Novak M: Truncated tau expression levels determine life span of a rat model of tauopathy without causing neuronal loss or correlating with terminal neurofibrillary tangle load. Eur J Neurosci 2008, 28:239-246.

86. Zilka N, Filipcik P, Koson P, Fialova L, Skrabana R, Zilkova M, Rolkova G, Kontsekova E, Novak M: Truncated tau from sporadic Alzheimer's disease suffices to drive neurofibrillary degeneration in vivo. FEBS Lett 2006, 580:3582-3588.

87. Lewis PA, Piper S, Baker M, Onstead L, Murphy MP, Hardy J, Wang R, McGowan E, Golde TE: Expression of BRI-amyloid beta peptide fusion proteins: a novel method for specific high-level expression of amyloid beta peptides. Biochim Biophys Acta 2001, 1537:58-62.

88. Lawlor PA, Bland RJ, Das P, Price RW, Holloway V, Smithson L, Dicker BL, During $M J$, Young D, Golde TE: Novel rat Alzheimer's disease models based on AAV-mediated gene transfer to selectively increase hippocampal Abeta levels. Mol Neurodegener 2007, 2:11.

89. Vidal R, Frangione B, Rostagno A, Mead S, Revesz T, Plant G, Ghiso J: A stopcodon mutation in the BRI gene associated with familial British dementia. Nature 1999, 399:776-781

90. Burns MP, Zhang L, Rebeck GW, Querfurth HW, Moussa CE: Parkin promotes intracellular Abeta1-42 clearance. Hum Mol Genet 2009, 18:3206-3216.

91. Rebeck GW, Hoe HS, Moussa CE: Beta-amyloid1-42 gene transfer model exhibits intraneuronal amyloid, gliosis, tau phosphorylation, and neuronal loss. J Biol Chem 2010, 285:7440-7446.

doi:10.1186/alzrt171

Cite this article as: Lecanu L, Papadopoulos V: Modeling Alzheimer's disease with non-transgenic rat models Alzheimer's Research \& Therapy 2013, 5:17. 